\title{
A PROTEÇÃO E PROMOÇÃO DOS DIREITOS HUMANOS DAS PESSOAS AFETADAS PELO TRÁFICO HUMANO E TRABALHO ESCRAVO NO BRASIL: UM ESTUDO SOBRE A PORTARIA N. 87/2020- MJSP
}

\author{
THE PROTECTION AND PROMOTION OF THE HUMAN RIGHTS OF PEOPLE AFFECTED \\ BY HUMAN TRAFFICKING AND SLAVE LABOR IN BRAZIL: A STUDY ON ORDINANCE N. \\ 87/2020-MJSP
}

\section{Mércia Cardoso de Souza}

Graduação em Serviço Social pela Universidade Estadual do Ceará, Graduação em Direito pela Universidade de Fortaleza, Mestrado em Direito Público pela Pontifícia Universidade Católica de Minas Gerais (bolsa Capes) e Doutorado em Direito Constitucional pela Universidade de Fortaleza. Estágio pré-doutoral no Departamento de Estudios Internacionales - Universidad Loyola Andalucía, Sevilla. Professora da Faculdade Luciano Feijão. Professora convidada da Esmec. Coordenadora da linha de pesquisa Direitos Humanos da Esmec. E-mail: merciacardosodesouza@gmail.com

\section{Mário Lúcio Quintão Soares}

Doutor e Mestre em Direito Constitucional pela Universidade Federal de Minas Gerais. Professor adjunto III da Pontifícia Universidade Católica de Minas Gerais, consultor da Coordenação de Aperfeiçoamento de Pessoal de Nível Superior (CAPES), ex-conselheiro Seccional da OAB/MG, ex-presidente da Comissão de Estudos Constitucionais da OAB/MG e membro do Instituto dos Advogados de Minas Gerais (IAMG).

E-mail: mlquintao@yahoo.com.br

\section{Guirino Dinis Jose Nhatave}

Mini Cv - Doutorando em Políticas Públicas pelo Programa de Pós-Graduação em Políticas Públicas da Universidade Estadual do Ceará (UECE). Mestre em Relações Internacionais e Diplomacia, com especialidade em Política Externa, pelo Instituto Superior de Relações Internacionais (ISRI). Pesquisador da linha de pesquisa Direitos Humanos, inserida no grupo de pesquisa Dimensões de Conhecimento do Poder Judiciário, da Escola Superior da Magistratura do Estado de Ceará (ESMEC). Bolsista do Programa de Estudantes-Convênio de Pós-Graduação, da CAPES-Brasil. E-mail: desgui69@gmail.com

Recebido em: $17 / 06 / 2020$

Aprovado em: 26/10/2020

RESUMO: A Portaria do Ministério da Justiça e Segurança Pública n. 87, de 23 de março de 2020, dispõe sobre a concessão e os procedimentos de autorização à pessoa que tenha sido vítima de tráfico de pessoas, de trabalho escravo ou de violação de direitos agravada pela sua condição migratória. Nesse sentido, essa norma se apresenta num plano maior em relação à Portaria n. 374, de 8 de maio de 2017, por ela revogada, vez que esta se referia somente à concessão de permanência no Brasil a estrangeiro considerado vítima de tráfico de pessoas. Mediante pesquisa bibliográfica e documental, com apoio da literatura estrangeira e suporte da internet, o presente artigo tem por 
objetivo analisar a relevância da Portaria n. 87/2020-MJSP para a proteção e promoção dos direitos humanos das pessoas afetadas pelo tráfico humano e trabalho escravo. Concluiu-se que a Portaria n. 87/2020-MJSP, ao dispor sobre os procedimentos de concessão de residência às vítimas, busca reduzir a vulnerabilidade dessas e garantir seu acesso aos direitos básicos, assim como a possibilidade de essas vítimas melhorarem sua condição de vulnerabilidade socioeconômica.

Palavras-chave: Tráfico de pessoas. Trabalho escravo. Concessão de residência. Brasil.

ABSTRACT: The Ordinance of the Ministry of Justice and Public Security n. 87, of March 23, 2020, provides for the granting and authorization procedures for the person who has been a victim of human trafficking, slave labor or violation of rights aggravated by his migratory condition. In this sense, this rule is presented in a larger plan in relation to Ordinance n.. 374, of May 8, 2017 , revoked by it, since this referred only to the grant of permanence in Brazil to foreigners considered victims of human trafficking. Through bibliographic and documentary research, with the support of foreign literature and the support of the internet, this article aims to analyze the relevance of Ordinance n. 87/2020-MJSP for the protection and promotion of the human rights of people affected by human trafficking and slave labor. It was concluded that Ordinance n. 87/2020-MJSP, by providing for the procedures for granting residence to victims seeks to reduce their vulnerability and ensure their access to basic rights, as well as the possibility of these victims improving their condition of socioeconomic vulnerability.

Keywords: Trafficking in persons. Slavery. Residence grant. Brazil

SUMÁRIO: Introdução. 1. Tráfico de pessoas e trabalho escravo: panorama internacional e brasileiro. 2. Portaria n. 87, de 23 de março de 2020. 3. Conclusões. Referências.

\section{INTRODUÇÃO}

De acordo com o Relatório Global sobre Tráfico de Pessoas de 2018, em escala mundial, os países estão identificando e denunciando mais vítimas de tráfico de pessoas e responsabilizando os criminosos que atuam como traficantes/aliciadores. Isso pode ser o resultado do aumento da capacidade de identificar vítimas e/ou do número de vítimas identificadas em situação de tráfico humano. De igual modo, o mesmo relatório aponta que um maior número de casos de tráfico foi reportado ao Escritório sobre Drogas e Crimes da Organização das Nações Unidas (UNODC), em 2016, que em qualquer outra época no período de 2005 a 2018. (UNODC, 2018).

Em resposta a esta problemática, muitos países alteraram suas legislações internas no sentido de criminalizar o tráfico de pessoas, conforme estabelecido no Protocolo Adicional à Convenção das Nações Unidas contra o Crime Organizado Transnacional Relativo à Prevenção, Repressão e Punição do Tráfico de Pessoas, em Especial Mulheres e Crianças (Protocolo de Palermo, 2000) ${ }^{1}$. Essa ação desenvolvida em, quase, todo mundo levou a um crescimento exponencial de países subscritores do Protocolo, de 33, em 2003, para 158, em 2016 (UNODC, 2016), assim como registro de 176 países em 2020 (UNODC, 2020), o que representa um aumento de 18 países que o subscreveram de 2016 a 2020, o que demonstra a crescente preocupação em prestar assistência às vítimas e a processar/julgar/responsabilizar os traficantes.

\footnotetext{
1 O Protocolo Adicional à Convenção das Nações Unidas contra o Crime organizado Transnacional Relativo à Prevenção, Repressão e Punição do Tráfico de Pessoas, em Especial Mulheres e Crianças foi adotado pela Organização das Nações Unidas (ONU), por meio da Resolução n. A/RES/55/25, em 15 de novembro de 2000, em Palermo, Itália, durante a 55 a Sessão da Assembleia Geral da ONU. Enquanto todos os Estados Partes da ONU assinaram a Convenção de Palermo, apenas oitenta apuseram assinatura, em um primeiro momento, no Protocolo que trata sobre o tráfico de pessoas. O Protocolo de Palermo (2000) possuía até em 03 de junho de 2020, 117 Signatários e 176 Estados Partes.
}

Revista de Direito Brasileira | Florianópolis, SC | v. 27 | n. 10 | p.358-373 | Set./Dez. 2020 
O Protocolo de Palermo (2000), no quadro de proteção às vítimas do tráfico de pessoas, dispõe, respectivamente, nos artigos $6^{\circ}, 7^{\circ}$ e $8^{\circ}$, referentes à assistência e proteção às vítimas de tráfico de pessoas, inclusive assegurando esses direitos nos Estados de acolhimento e repatriamento dessas vítimas. Desse modo, os Estados Partes também devem considerar a provisão da integridade física das vítimas e a provisão de moradia, aconselhamento, assistência médica, psicológica e material, bem como oportunidades laborais e educacionais para as vítimas de tráfico. (UNODC, 2016)

No Brasil, a proteção às vítimas de tráfico está salvaguardada na Lei n. 13.344, de 6 de outubro de $2016^{2}$, especificamente, nos seus artigos $6^{\circ}$ e $7^{\circ}$, que dispõem sobre a proteção e atendimento à vítima direta ou indireta do tráfico de pessoas e nos acréscimos dos artigos 18-A e 42-A, na Lei n. $6.815^{3}$, de 19 de agosto de 1980 , respectivamente.

O tráfico de pessoas no mundo, assim como no Brasil tem revestido as modalidades de tráfico internacional e interno de pessoas, apresentando finalidades diversas, sendo as mais frequentes no Brasil, a exploração sexual e o trabalho forçado ${ }^{4}$ (MINISTÉRIO DA JUSTIÇA, 2017), cuja denominação utilizada pelo país é o trabalho escravo (submissão de pessoa à condição análoga à de escravo $)^{5}$.

Com relação à problemática do trabalho forçado, tal prática vem sendo discutida desde a Convenção n. 29 (1930) sobre o trabalho forçado ou obrigatório da lavra da Organização Internacional do Trabalho (OIT) ${ }^{6}$. No Código Penal Brasileiro (CPB) essa questão consta do art. $149^{7}$ (BRASIL, 2003). Porém, o seu conteúdo foi alterado em 2003, pela Lei n. 10.803, de 11 de dezembro, que "representa um avanço no sentido de identificar a caracterização do trabalho em condições análogas à de escravo" (SOUZA, 2016, p. 192). De igual modo, a alteração conceitual trazida pela Lei n. 13.344, de 6 de outubro, com o acréscimo do art. 149-A ${ }^{8}$ (BRASIL, 2016), é uma relevante contribuição para o aperfeiçoamento semântico e a sua relação com o tráfico humano.

Assim, a Portaria do Ministério da Justiça e Segurança Pública (MJSP) n. 87, de 23 de março de 2020, ao dispor sobre a concessão e os procedimentos de autorização à pessoa que tenha sido vítima de tráfico de pessoas, de trabalho escravo ou de violação de direitos agravada pela sua condição migratória, surge como manifestação do Estado brasileiro em providenciar a assistência às vítimas estabelecida no Protocolo de Palermo, bem assim pelas normas brasileiras.

\footnotetext{
${ }^{2}$ Novo marco legal brasileiro sobre o tráfico de pessoas.

${ }^{3}$ Estatuto de Estrangeiro.

${ }^{4}$ MINISTÉRIO DA JUSTIÇA. Relatório nacional sobre o tráfico de pessoas: dados 2014 a 2016. Brasília: UNODC, 2017. Disponível em: <https://www.justica.gov.br/sua-protecao/trafico-de-pessoas/publicacoes/relatorio-dedados.pdf>. Acesso em: 21 maio 2020.

${ }^{5} \mathrm{O}$ tráfico de pessoas para fins de trabalho forçado não era criminalizado pelo CPB até outubro de 2016.

${ }^{6}$ A Convenção foi aprovada pelo Brasil, em 1957, mediante o Decreto legislativo n. 24, de 25 de maio de 1956 e ratificado pelo Decreto n. 41.721, de maio de 1957. Disponível em: < http://pfdc.pgr.mpf.mp.br/atuacao-e-conteudosde-apoio/legislacao/trabalho-escravo/convencao_n_29.pdf>. Acesso em: 5 jun. 2020.

${ }^{7}$ Art. 149- Reduzir alguém a condição análoga à de escravo, quer submetendo-o a trabalhos forçados ou a jornada exaustiva, quer sujeitando-o a condições degradantes de trabalho, quer restringindo, por qualquer meio, sua locomoção em razão de dívida contraída com o empregador ou preposto: (Redação dada pela Lei $\mathrm{n}^{\mathrm{o}} 10.803$, de 11.12.2003).

${ }^{8}$ Art. 149-A. Agenciar, aliciar, recrutar, transportar, transferir, comprar, alojar ou acolher pessoa, mediante grave ameaça, violência, coação, fraude ou abuso, com a finalidade de: (Incluído pela Lei no 13.344, de 2016) (Vigência).

I - remover-lhe órgãos, tecidos ou partes do corpo; (Incluído pela Lei no 13.344, de 2016) (Vigência)

II - submetê-la a trabalho em condições análogas à de escravo; (Incluído pela Lei no ${ }^{\circ}$ 13.344, de 2016) (Vigência).

III - submetê-la a qualquer tipo de servidão; (Incluído pela Lei nº 13.344, de 2016) (Vigência)

IV - adoção ilegal; ou (Incluído pela Lei no 13.344 , de 2016) (Vigência).

V - exploração sexual. (Incluído pela Lei no 13.344 , de 2016) (Vigência).

Pena - reclusão, de 4 (quatro) a 8 (oito) anos, e multa. (Incluído pela Lei nº 13.344, de 2016) (Vigência).
} 
O presente trabalho está subdividido em duas partes, além da introdução e a conclusão. A primeira seção aborda sobre o panorama internacional e brasileiro sobre o tráfico de pessoas e o trabalho escravo. A segunda e última seção analisa a interface entre a Portaria n. 87/2020-MJSP e a legislação atinente ao enfrentamento ao tráfico de pessoas e o trabalho escravo no Brasil. Ao final, são traçadas as conclusões.

\section{TRÁFICO DE PESSOAS E TRABALHO ESCRAVO: PANORAMA INTERNACIONAL E BRASILEIRO}

A expressão "tráfico de pessoas" significa transferir e/ou reter uma pessoa por meio da força ou da coerção, a fim de explorá-la para diversas finalidades, sendo as mais expressivas no Brasil: sexual, trabalhos forçados (trabalho escravo), remoção de órgãos, casamento forçado, delitos e outras atividades (UNODC, 2018). Conforme consta no Protocolo de Palermo, a expressão "tráfico de pessoas" é conceituada como:

[...] o recrutamento, o transporte, a transferência, o alojamento ou o acolhimento de pessoas, recorrendo à ameaça ou uso da força ou a outras formas de coação, ao rapto, à fraude, ao engano, ao abuso de autoridade ou à situação de vulnerabilidade ou à entrega ou aceitação de pagamentos ou benefícios para obter o consentimento de uma pessoa que tenha autoridade sobre outra para fins de exploração. A exploração incluirá, no mínimo, a exploração da prostituição de outrem ou outras formas de exploração sexual, o trabalho ou serviços forçados, escravatura ou práticas similares à escravatura, a servidão ou a remoção de órgãos. (ONU, 2000)

O Brasil assinou em 2000 e ratificou em 2004 o Protocolo de Palermo (2000), por meio do Decreto n. 5.017, de 12 de março de 2004, pelo qual se obrigou a enfrentar o tráfico de pessoas, a partir de mudanças legislativas, elaboração e implementação de políticas públicas, dentre outras ações.

Diante desse compromisso o Brasil aprovou a Política Nacional de Enfrentamento ao Tráfico de Pessoas, por meio do Decreto n. 5.948, de 26 de outubro de 2006, que contém princípios e diretrizes pautados na proteção e promoção dos direitos humanos, além de uma abordagem transversal da temática ${ }^{9}$ (BRASIL, 2006). Como forma de reforçar a concretização dessa Política, em 2008, 2013 e 2018 o Brasil aprovou, respectivamente, o I, II e III Planos Nacionais de Enfrentamento ao Tráfico de Pessoas.

Visto sob ponto de vista cronológico, mediante o Decreto n. 6.347, de 8 de janeiro de 2008, o Brasil aprovou o I Plano Nacional de Enfrentamento ao Tráfico de Pessoas (PNETP) e instituiu o Grupo Assessor de Avaliação e Disseminação do referido plano. Tratou-se de uma tarefa delegada ao Grupo de Trabalho Interministerial (GTI), formado por representantes de diversos órgãos públicos federais, e a colaboração do Ministério Público Federal, do Ministério Público do Trabalho e da sociedade civil, incluindo organizações não-governamentais, especialistas e organismos internacionais. (MINISTÉRIO DA JUSTIÇA, 2008)

O referido Plano foi sistematizado a partir de três eixos: prevenção, atenção às vítimas e repressão, tendo como objetivo delinear as principais atividades a serem desenvolvidas por todos os atores envolvidos no enfrentamento ao tráfico de pessoas. Todavia, apesar de observar que a elaboração do Plano, assim como da Política Nacional de Enfrentamento ao Tráfico de Pessoas, que representam um avanço para o enfrentamento ao tráfico de pessoas, não tiveram condições de dar subsídios para um enfrentamento ao tráfico de pessoas de modo satisfatório devido aos diversos

\footnotetext{
${ }^{9}$ BRASIL. Decreto n. 5.948, de 26 de outubro de 2006. Aprova a Política Nacional de Enfrentamento ao Tráfico de Pessoas e institui Grupo de Trabalho Interministerial com o objetivo de elaborar proposta do Plano Nacional de Enfrentamento ao Tráfico de Pessoas - PNETP. Disponível em: < http://www.planalto.gov.br/ccivil_03/_Ato20042006/2006/Decreto/D5948.htm>. Acesso em: 13 maio 2020.
} 
aspectos que perpassam o delito, as contradições constantes nos instrumentos normativos, que ocasionam dificuldades para a atuação dos profissionais que lidam diariamente com o tema, implicam em confusões conceituais que vêm prejudicar a tipificação do delito, a identificação dos criminosos e das vítimas. (LIMA, 2012)

Em seguida foi aprovado o II Plano Nacional de Enfrentamento ao Tráfico de Pessoas, por meio da Portaria Interministerial n. 634, de 25 de fevereiro de 2013, editado dois anos após término do primeiro, consubstanciando, desse modo, o segundo processo de planejamento nacional. À semelhança do primeiro, esse II Plano foi "elaborado por meio de um amplo processo de diálogos que resultou em sugestões de ações a serem implementadas pelo governo brasileiro por meio de políticas públicas integradas para enfrentar o tráfico de pessoas interno e internacional". (MINISTÉRIO DA JUSTIÇA, 2013, p. 8)

Passados dez anos após a elaboração do I Plano, o Brasil aprovou o III Plano Nacional de Enfrentamento ao Tráfico de Pessoas, por intermédio do Decreto n. 9.440, de 3 de julho de 2018, no qual os incisos I e II do art. $2^{\circ}$ mencionam como objetivos: ampliar e aperfeiçoar a atuação da União, dos Estados, do Distrito Federal e dos Municípios no enfrentamento ao tráfico de pessoas, na prevenção e repressão do crime de tráfico de pessoas, na responsabilização de seus autores, na atenção a suas vítimas e na proteção dos direitos de suas vítimas e fomentar e fortalecer a cooperação entre os órgãos públicos, as organizações da sociedade civil e os organismos internacionais no Brasil e no exterior envolvidos no enfrentamento ao tráfico de pessoas ${ }^{10}$. (BRASIL, 2018)

Com efeito, conhecido como sendo um instrumento de construção coletiva por agregar valores do II Plano, que vigorou de 2013 a 2016, mas também por assumir uma dimensão de transversalidade e colaboração, tanto em sua implementação como em seu monitoramento, o III Plano se serve das demandas que buscam suas origens na adoção da Lei n. 13.344, de 6 de outubro de 2016 (novo marco legal do Brasil), por ter trazido um conceito amplo de tráfico de pessoas, considerando variadas modalidades de exploração, prevendo a elaboração de políticas públicas, a atuação dos sistemas de justiça, dentre outras.

Nessa senda, a temática do tráfico de pessoas é assunto de interesse do Conselho Nacional de Justiça (CNJ), o que se pode constatar com base nos seguintes documentos: $i$ ) Portaria n. 5, de 15 de janeiro de 2016, que criou o Comitê Nacional Judicial de Enfrentamento à Exploração do Trabalho em Condição Análoga à de Escravo e ao Tráfico de Pessoas; ii) Resolução n. 212, de 15 de dezembro de 2015, que instituiu o Fórum Nacional do Poder Judiciário para Monitoramento e Efetividade das Demandas Relacionadas à Exploração do Trabalho em Condições Análogas à de Escravo e ao Tráfico de Pessoas (FONTET), com o objetivo de elaborar estudos e propor medidas para o aperfeiçoamento do sistema judicial quanto ao tema. iii) Compromisso por meio do Acordo de Cooperação Técnica n. 14, assinado em 18 de agosto de 2015, que tem o objetivo da conjugação de esforços entre as entidades signatárias para o fortalecimento, a consolidação e a replicação do Projeto "Ação Integrada", por meio do Movimento Ação Integrada, destinado a criar condições para a modificação social, educacional e econômica dos egressos do trabalho em condição análoga à de escravo e de trabalhadores em situação de vulnerabilidade. $i v$ ) Em dezembro de 2018 o CNJ acolheu a Agenda Global 2030, que é um compromisso assumido por líderes de 193 países, incluindo o Brasil, coordenada pela ONU, por meio do Programa das Nações Unidas para o Desenvolvimento (PNUD), nos termos da Resolução A/RES/72/279 (AG/ONU). São 17 os Objetivos de Desenvolvimento Sustentável e 169 Metas a serem realizadas no período de 2016 a 2030. Tais objetivos e metas estão relacionados à efetivação dos direitos humanos e promoção do desenvolvimento, que incorporam e dão continuidade aos 8 Objetivos de Desenvolvimento do Milênio, a partir de subsídios construídos na Rio+20. v) Por meio da Portaria n. 133/2018, foi

\footnotetext{
${ }^{10}$ BRASIL. Decreto n. 9.440, de 3 de julho de 2018. Aprova o III Plano Nacional para o Enfrentamento ao Tráfico de Pessoas. Disponível em: <https://www.justica.gov.br/sua-protecao/trafico-de-pessoas/politica-brasileira/dec-944018-iii-plano.pdf>. Acesso em: 15 maio 2020.
} 
instituído no CNJ, o Comitê Interinstitucional destinado a avaliar a integração das metas do Poder Judiciário às metas e indicadores dos Objetivos de Desenvolvimento Sustentável (ODS), Agenda 2030, e elaborar relatório de trabalho com apoio de todos os tribunais do país, cuja composição consta na Portaria n. 148/2018-CNJ ${ }^{11}$. (CONSELHO NACIONAL DE JUSTIÇA, 2020)

Ademais, o Brasil conta com a Rede de Enfrentamento ao Tráfico de Pessoas ${ }^{12}$, que é composta por Núcleos de Enfrentamento ao Tráfico de Pessoas ${ }^{13}$, Postos Avançados de Atendimento Humanizado ao Migrante $^{14}$ e Comitês Estaduais de Enfrentamento ao Tráfico de Pessoas $^{15}$. (MINISTÉRIO DA JUSTIÇA E SEGURANÇA PÚBLICA, 2020)

É curial ressaltar que o tráfico de pessoas é uma atividade criminosa que vem preocupando todo o mundo, conforme divulgado nos vários Relatórios elaborados pelo UNODC. O Relatório sobre Tráfico de Pessoas (2018) destaca que mais de $70 \%$ das pessoas afetadas pelo tráfico em nível global é do sexo feminino. Os dados evidenciam que o tráfico de pessoas tem afetado mais seres humanos a cada ano, possuindo um inexorável recorte de gênero, vez que a maior parte das vítimas é composta por mulheres adultas (49\%) e adolescentes (meninas) (23\%). Os homens constituem $21 \%$ das vítimas e os meninos $7 \%$ do seu cômputo global. (UNODC, 2018)

Enquanto a maioria das vítimas de exploração sexual é do sexo feminino, os homens formam o maior grupo nos casos de trabalho forçado. Embora a finalidade mais divulgada seja o tráfico de pessoas para exploração sexual, milhares de vítimas também trabalham em condições análogas à escravidão em serviços domésticos e em setores como mineração, pesca e, por vezes, são utilizadas para a mendicância infantil e o tráfico para remoção de órgãos humanos. (UNODC, 2018)

Os grupos criminosos se beneficiam da situação de vulnerabilidade das vítimas, que é maior nas zonas de conflito devido à falta de atenção do Estado, ao deslocamento da população, à fragmentação familiar e à necessidade de bens básicos. (UNODC, 2018)

Por sua vez, o Brasil tem sido afetado pelo delito de tráfico de pessoas, tanto nas modalidades internacional e interna de pessoas. Aqui as duas formas de exploração mais frequentes são a sexual e o trabalho forçado, cuja denominação utilizada pelo país é a submissão de pessoa à condição análoga à de escravo (art. 149, CP). Enquanto a primeira forma de exploração tem como grupo mais afetado o de mulheres e adolescentes do sexo feminino, a segunda tem como principal grupo atingido o de homens e adolescentes do sexo masculino.

Outrossim, o tráfico de pessoas para trabalho escravo afeta homens brasileiros, e em menor grau, mulheres e crianças, que são submetidos a essa prática ilícita em áreas rurais (em fazendas de gado, na produção de carvão vegetal, nos campos e nas plantações de cana), na exploração de madeira, na mineração e agricultura; indústria têxtil, sobretudo de estrangeiros; no setor de turismo (turismo para fins sexuais, trabalho em cruzeiros); na construção civil e nos megaeventos (SOUZA, 2016). Por outro lado, o estudo publicado pelo Instituto de Pesquisa Econômica Aplicada (IPEA) revelou que as denúncias recebidas pela Comissão Pastoral da Terra (CPT), no período de 2008-2016, foram marcadas pelo trabalho escravo nos seguintes setores:

\footnotetext{
${ }^{11}$ CONSELHO NACIONAL DE JUSTIÇA. Portaria n. 133/2018. Institui o Comitê Interinstitucional destinado a avaliar a integração das metas do Poder Judiciário às metas e indicadores dos Objetivos de Desenvolvimento Sustentável (ODS), Agenda 2030. Disponível em: 〈https://atos.cnj.jus.br/atos/detalhar/2721〉. Acesso em: 10 jun. 2020.

${ }^{12}$ Conjunto instituições e atores envolvidos no processo de enfrentamento ao tráfico de pessoas. Essas instituições, de acordo com suas respectivas atribuições, são responsáveis por materializar os princípios da Política Nacional de Enfrentamento ao Tráfico de Pessoas nos estados e municípios.

${ }^{13}$ Nas seguintes unidades da Federação: Acre, Amapá, Amazonas, Bahia, Ceará, Distrito Federal, Goiás, Maranhão, Mato Grosso, Minas Gerais, Pará, Paraná, Pernambuco, Rio de Janeiro, Rio Grande do Sul e São Paulo.

${ }^{14}$ Nas seguintes unidades da Federação: Amazonas, Ceará, Pará, Rio de Janeiro e São Paulo.

${ }^{15}$ Nas seguintes unidades da Federação: Acre, Alagoas, Amazonas, Bahia, Ceará, Distrito Federal, Goiás, Maranhão, Minas Gerais, Pará, Paraná, Pernambuco, Rio de Janeiro, Rio Grande do Sul, São Paulo, Mato Grosso do Sul, Mato Grosso, Paraíba e Roraima.
}

Revista de Direito Brasileira | Florianópolis, SC | v. 27 | n. 10 | p.358-373 | Set./Dez. 2020 
cana-de-açúcar, desmatamento, pecuária, roça de pasto (ou juquira), carvão vegetal, mineração e lavouras temporárias, ligadas à abertura de pastagens e à pecuária. (ARBEX; GALIZA; OLIVEIRA, 2018).

Essa forma de exploração, como já havia sido observada por Waldimeiry Corrêa da Silva, se encontra dissimulada por métodos sutis na sociedade, extraindo benefícios diretos e indiretos por meio da exploração do trabalho (CORRÊA DA SILVA, 2018). Com efeito, a escravidão contemporânea, na perspectiva da autora é um gênero que se reveste de distintas instituições jurídicas: escravidão; tráfico de escravos; trabalho forçado; servidão por dívida; servidão rural; matrimônio forçado; exploração infantil; tráfico de seres humanos. Compreende-se, em suma, que quando uma pessoa está submetida a um trabalho contra sua vontade, sob ameaça de violência ou qualquer forma de coação ou castigo, se encontra restringida sua liberdade, além de exercer sobre ela os atributos do direito de propriedade ou alguns desses; fato que se contempla desde o tráfico de pessoas e sua exploração, mediante trabalho forçado, como forma contemporânea de escravidão (CORRÊA DA SILVA; GOES, 2013; CORRÊA DA SILVA, 2018).

[...] a situação análoga à escravidão também se configura mediante "os atributos de propriedade que são exercidos" diretamente sobre uma pessoa, além da privação da liberdade e "espólio" de sua dignidade, ao submetê-la ao trabalho sob ameaça e coação. (CORRÊA DA SILVA, 2018, p. 37)

No tocante ao trabalho forçado em escala global o estudo elaborado, em parceria em 2017, pela OIT, Walk Free Foundation e Organização Internacional para as Migrações (OIM) estimava que cerca de 40,3 milhões de pessoas eram vítimas de algum tipo de escravidão moderna. Desse total, cerca de 25 milhões de pessoas foram submetidas a trabalho forçado e 15,4 milhões foram forçadas a se casar (INTERNATIONAL LABOUR ORGANIZATION; WALK FREE FOUNDATION; INTERNATIONAL ORGANIZATION FOR MIGRATION, 2017). Das 24,9 milhões de pessoas submetidas a trabalho forçado, 16 milhões foram exploradas no setor privado (por ex. trabalho doméstico, construção ou agricultura), 4,8 milhões sofreram exploração sexual e 4 milhões se encontravam em situação de trabalho forçado imposto por autoridades de governos. Ademais, a OIT estima que as mulheres representem $99 \%$ das vítimas do trabalho forçado (fins de exploração sexual comercial) e $84 \%$ dos casamentos forçados (matrimônios forçados). Com relação às crianças, representam uma em cada quatro vítimas da escravidão moderna. Já no tocante aos trabalhadores migrantes e os povos indígenas são particularmente vulneráveis ao trabalho forçado (ORGANIZAÇÃO INTERNACIONAL DO TRABALHO, s/d).

A Walk Free Foundation publicou em 2018 o Índice Global de Escravidão Moderna, revelando algumas especificidades da escravidão contemporânea e tráfico de pessoas. Nesse estudo se apresenta um espectro histórico da dimensão do problema no Brasil, assim como no mundo, por meio do qual é relatado que essa modalidade inclui situações em que pessoas são presas a um contratante por dívida assumida, ou mantidas como trabalhadores domésticos para pagar por um serviço. Trata-se de um problema cujos fatores causais estão associados à migração, conflitos, regimes repressivos e discriminação (WALK FREE FOUNDATION, 2018).

De acordo com o mesmo relatório, o Brasil, com estimativa de 369 mil pessoas submetidas ao trabalho escravo, é o $20^{\circ}$ colocado em uma lista de 27 países no continente americano (WALK FREE FOUNDATION, 2018).

Nesse diapasão, o Tribunal Penal Internacional Ad Hoc para a antiga Iugoslávia, ao prolatar a sentença de primeira instância, estabeleceu alguns critérios para identificar uma situação de escravidão ou redução à servidão: a) restrição ou controle da autonomia individual, a liberdade de escolha ou a liberdade de movimento de uma pessoa; b) a obtenção de um benefício por parte do perpetrador; c) a ausência de consentimento ou do livre arbítrio da vítima, ou sua impossibilidade ou irrelevância devido à ameaça de uso da violência ou outras formas de coerção, medo de violência, fraude ou falsas promessas; d) o abuso de poder; e) a posição de vulnerabilidade 
da vítima; f) a detenção ou cativeiro; g) a opressão psicológica em virtude de condições socioeconômicas; h) a exploração; i) a extração de trabalho ou serviços forçados ou obrigatórios, em geral sem remuneração (TPIY, 2001) ${ }^{16}$

While hesitating as to how to interpret the definition of slavery, the international jurisprudence has gravited towards and understanding of the nature of slavery. That slavery is ultimately about control. Control which deprives a person, in a significant manner, of their individual liberty or autonomy; and ultimately, that this control is meant to allow for exploitation and its typically maintained through coercion or violence. (ALLAIN, 2013, p. 120) ${ }^{17}$

Evidencia-se que o trabalho escravo é permeado por uma relação de poder em que o escravo presta obediência ao seu explorador. Nesse sentido, a categoria da escravidão possui três características: é incomum, tanto pela intensidade máxima do poder envolvido e em tudo o que isso implica, como pelas qualidades da coerção que produzem e mantém a relação; tem condição individualizada, vez que o escravo é impotente em relação a outro indivíduo (escravizador); a escravidão era uma alternativa à morte na guerra. (PATTERSON, 2008, pp. 19-23).

No Brasil - de forma distinta da América Latina - as principais vítimas do trabalho escravo contemporâneo não são povos indígenas amazônicos, mas trabalhadores não brancos (pretos e pardos) oriundos da Região Nordeste, notadamente, dos estados mais pobres e com menos perspectiva de trabalho e emprego (SAKAMOTO, 2020). De acordo com o Observatório da Erradicação do Trabalho Escravo e do Tráfico de Pessoas, as regiões onde foram resgatados mais trabalhadores em situação de trabalho escravo no período 2003-2018 foram: Pará (10.043 vítimas resgatadas), Mato Grosso (4.394 vítimas resgatadas) e Goiás (3.944 trabalhadores resgatados). (OBSERVATÓRIO DA ERRADICAÇÃO DO TRABALHO ESCRAVO E DO TRÁFICO DE PESSOAS, 2020). ${ }^{18}$

Asseveram Corrêa da Silva e Góes que a proteção contra as formas contemporâneas de escravidão não está prevista de maneira expressa na Constituição Federal de 1988 (CF/88). Porém, esse fato não significa que tal proteção não tenha status constitucional. Sua justificação é baseada no fato da $\mathrm{CF} / 88$ estabelecer a dignidade humana e o valor social do trabalho como fundamentos da República Federativa do Brasil, pois o texto constitucional ao estabelecer a igualdade e a liberdade como direitos fundamentais deu importância ao tema em apreço. Além disso, a jurisprudência do Supremo Tribunal Federal impõe ao Estado brasileiro o respeito à esfera individual de todos os cidadãos (CORRÊA DA SILVA; GOES, 2013).

A reafirmação, do Brasil, na salvaguarda dos direitos humanos e fundamentais, na dignidade e no valor da pessoa humana assenta na assinatura e ratificação de instrumentos internacionais de Direitos Humanos, por intermédio dos quais é assegurado o respeito ao princípio

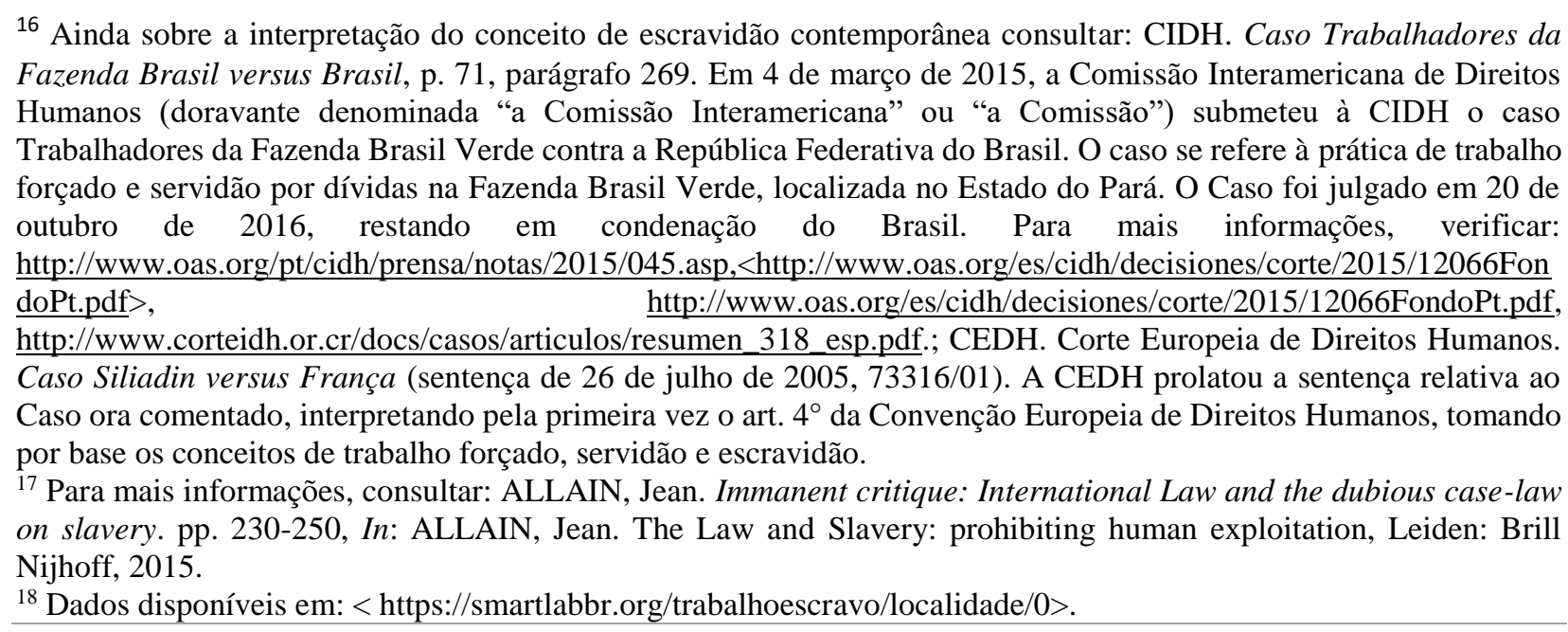
Revista de Direito Brasileira | Florianópolis, SC | v. 27 | n. 10 | p.358-373 | Set./Dez. 2020 
da dignidade humana, como a Declaração Universal dos Direitos Humanos, a Declaração sobre os Objetivos e Propósitos da Organização Internacional do Trabalho (conhecida como Declaração da Filadélfia), promulgada no Brasil por meio do Decreto n. 25.696, de 20 de dezembro de 1948 (CORREAA DA SILVA; GOES, 2013). Assim como o seu comprometimento em suprimir todas as formas de trabalho forçado e obrigatório, ao ratificar a Convenção n. 29 (1930) sobre o Trabalho Forçado ou Obrigatório, por intermédio do Decreto n. 41.721, de maio de 1957.

Ainda no quadro desse aparato constitucional, observa-se, no ano de 1999, um forte mecanismo de desincentivo ao uso desumano da força de trabalho, mediante a apresentação da Proposta de Emenda Constitucional (PEC) n. 438, que propunha nova redação ao art. 243 da Constituição Federal de $1988(\mathrm{CF} / 88)^{19}$. Na sequência, os defensores de punições mais rígidas por crimes de escravidão advogam que o artigo seja emendado para incluir o emprego de trabalho escravo como um dos crimes que justificariam a expropriação (FIGUEIRA; ESTERCI, 2017). Embora esse esforço fosse sinal de grande avanço, nessa altura, não logrou devidos efeitos positivos, pois a proposta aguardava a aprovação em segunda votação na Câmara dos Deputados, após votação em 2012, no Senado Federal, depois de muita resistência (SALES; FIGUEIRA, 2013). Contudo, o conceito de escravidão contemporânea, restrito inicialmente, no art. $149^{20}$, do Código Penal de 1940, foi associado à (CF/88), na forma do artigo 243, graças à Emenda Constitucional (EC) n. 81/2014 (BRASIL, 2014) ${ }^{21}$, após anos de debates no parlamento brasileiro (FIGUEIRA; PRADO; PALMEIRA, 2017).

Essas referidas transformações legislativas que passaram, também, pela alteração do conteúdo do art. $149^{22}$ do CP, por meio da Lei n. 10.803, de 11 de dezembro de 2003, forneciam o amparo legal necessário às ações de combate ao trabalho escravo no Brasil. É mediante esse esforço, que recentemente, com a adoção da Lei n. 13.344/2016, essa questão passou a merecer especial atenção como determina o art. 13 desta norma.

Com efeito, a partir da aprovação da referida Lei, o CP passou a vigorar acrescido do art. 149- $\mathrm{A}^{23}$, ampliando o conceito de tráfico de pessoas e tipificando vários tipos de exploração no

19 O art. 243 da Constituição de 1988, trata do confisco de propriedades onde forem encontradas lavouras de psicotrópicas ilegais. A PEC estende a expropriação sem direito à indenização para casos de exploração do trabalho análoga à escravidão. A proposta define ainda que as propriedades confiscadas sejam destinadas ao assentamento de famílias para contribuir com a reforma agrária.

${ }^{20}$ A redação original do artigo 149 do Código Penal Brasileiro, antes da alteração introduzida pela Lei n. 10.803/2003, limitava-se a tipificar a conduta de "reduzir alguém à condição análoga à de escravo". O alto grau de generalidade do texto não fornecia aos juízes criminais elementos objetivos à identificação das formas pelas quais se reduz a vítima à condição análoga à de escravo (ORGANIZAÇÃO INTERNACIONAL DE TRABALHO, 2010, p. 33).

${ }^{21}$ Emenda Constitucional n. 81, de 5 de junho de 2014, dá nova redação ao art. 243 da Constituição Federal. Disponível em:

<http://www.planalto.gov.br/ccivil_03/constituicao/Emendas/Emc/emc81.htm\#: :text=EMENDA\%20CONSTITUC IONAL $\% 20$ N\%C2\%BA\%2081\%2C\%20DE,do\%20\%C2\%A7\%203\%C2\%BA\%20do\%20art.>. Acesso em: 14 jun. 2020.

${ }^{22}$ Por força do art. $1^{\circ}$ dessa norma, da Lei n. 10.803 de 11 de dezembro de 2003, o art. 149 passou a vigorar com a seguinte redação: Artigo 149. Reduzir alguém à condição análoga à de escravo, quer submetendo-o a trabalhos forçados ou a jornada exaustiva, quer sujeitando-o a condições degradantes de trabalho, quer restringindo, por qualquer meio, sua locomoção em razão de dívida contraída com o empregador ou preposto. Pena - reclusão, de 2 (dois) a 8 (oito) anos, e multa, além da pena correspondente à violência. $§ 1^{\circ}$ Nas mesmas penas incorre quem: I - cerceia o uso de qualquer meio de transporte por parte do trabalhador, com o fim de retê-lo no local de trabalho; II - mantém vigilância ostensiva no local de trabalho ou se apodera de documentos ou objetos pessoais do trabalhador, com o fim de retê-lo no local de trabalho. $\$ 2^{\circ}$ A pena é aumentada de metade, se o crime é cometido: I - contra criança ou adolescente; II - por meio de preconceito de raça, cor, etnia, religião ou origem.

${ }^{23}$ Tráfico de Pessoas

Art. 149-A. Agenciar, aliciar, recrutar, transportar, transferir, comprar, alojar ou acolher pessoa, mediante grave ameaça, violência, coação, fraude ou abuso, com a finalidade de:

I - remover-lhe órgãos, tecidos ou partes do corpo;

II - submetê-la a trabalho em condições análogas à de escravo;

III - submetê-la a qualquer tipo de servidão;

Revista de Direito Brasileira | Florianópolis, SC | v. 27 | n. 10 | p.358-373 | Set./Dez. 2020 
contexto do delito (remoção de órgãos, tecidos e partes do corpo; submissão a trabalho em condições análogas à de escravo; qualquer tipo de servidão; adoção ilegal; exploração sexual).

No entanto, a Lei sobre o enfrentamento ao tráfico de pessoas, para além de providenciar um conceito mais amplo de tráfico de pessoas, considerando o tráfico para várias modalidades de exploração, constitui um avanço no tocante à prevenção e repressão a este ilícito penal, pois diferente do texto antigo do CP, que abordava apenas a exploração sexual, a lei ampliou as formas de exploração, fato que fortalece os mecanismos de prevenção e repressão ao tráfico interno e internacional, assim como a necessidade de implementação de medidas de atenção às vítimas.

\section{PORTARIA N. 87, DE 23 DE MARÇO DE 2020}

O Ministério da Justiça e Segurança Pública aprovou a Portaria n. 87, de 23 de março de 2020, que dispõe sobre a concessão e os procedimentos de autorização de residência à pessoa que tenha sido vítima de tráfico de pessoas ${ }^{24}$, de trabalho escravo ${ }^{25}$ ou de violação de direitos agravada pela sua condição migratória (BRASIL, 2020) ${ }^{26}$. Essa decisão, que decorre das competências constitucionais e específicas do órgão, e da operacionalização da legislação brasileira sobre o tráfico de pessoas, a migração, o trabalho escravo, trouxe modificações relevantes no ordenamento jurídico brasileiro, com especial enfoque a proteção e promoção dos direitos humanos das pessoas vítimas de tráfico e trabalho escravo.

No que concerne às competências constitucionais, os incisos I e II do parágrafo único do art. 87 da CF/88 predispõe que compete ao Ministro de Estado, no caso em debate ao Ministro da Justiça e Segurança Pública, "exercer a orientação, coordenação e supervisão dos órgãos e entidades da administração federal na área de sua competência e referendar os atos e decretos assinados pelo Presidente da República" e "expedir instruções para a execução das leis, decretos e regulamentos" (BRASIL, 1988). Tais competências são reafirmadas, de forma específica, pela Lei n. 13.844, de 18 de junho de 2019, inciso V do art. 37 que, dentre outras atribuições, prevê como competências do Ministério da Justiça e Segurança Pública (MJSP) atender a questões relacionadas à "nacionalidade, imigração e estrangeiros", assim como pelo Decreto n. 9.662, de $1^{\circ}$ de janeiro de 2019, que no art. $8^{\circ}$ preceitua que o MJSP será responsável pela tomada de medidas em relação à

IV - adoção ilegal; ou

V - exploração sexual.

Pena - reclusão, de 4 (quatro) a 8 (oito) anos, e multa.

$\S 1^{\circ}$ A pena é aumentada de um terço até a metade se:

I - o crime for cometido por funcionário público no exercício de suas funções ou a pretexto de exercê-las;

II - o crime for cometido contra criança, adolescente ou pessoa idosa ou com deficiência;

III - o agente se prevalecer de relações de parentesco, domésticas, de coabitação, de hospitalidade, de dependência econômica, de autoridade ou de superioridade hierárquica inerente ao exercício de emprego, cargo ou função; ou IV - a vítima do tráfico de pessoas for retirada do território nacional.

$\S 2^{\circ}$ A pena é reduzida de um a dois terços se o agente for primário e não integrar organização criminosa. (BRASIL, 2016)

${ }^{24}$ De acordo com o inciso I do art. $3^{\circ}$, da Portaria n. 87, de 23, de março de 2020, considera-se vítima de tráfico de pessoas: o imigrante aliciado, recrutado, transportado do exterior, transferido, comprado, alojado, acolhido ou mantido em território nacional, mediante grave ameaça, violência, coação, fraude ou abuso de poder, com a finalidade de: a) remover-lhe órgãos, tecidos ou partes do corpo; b) submetê-lo a trabalho em condições análogas à de escravo; c) submetê-lo a qualquer tipo de servidão; d) adoção ilegal; ou e) exploração sexual.

${ }^{25}$ De acordo com o inciso II do art. $3^{\circ}$, da Portaria n. 87, de 23, de março de 2020, considera-se vítima de trabalho escravo: o imigrante reduzido à condição análoga à de escravo, seja pela submissão a trabalhos forçados ou jornada exaustiva, condições degradantes de trabalho, restrição da sua locomoção em razão de dívidas contraídas com o empregador, ou retenção de documentos ou objetos pessoais com o fim de retê-lo no trabalho.

${ }^{26}$ De acordo com o inciso II do art. $3^{\circ}$, da Portaria n. 87, de 23, de março de 2020, considera-se vítima de violação de direito agravada por sua condição migratória: o imigrante que tenha sofrido violência doméstica, cárcere privado, extorsão ou tortura, cujo autor do delito se prevaleceu da condição migratória da vítima. 
Coordenação-Geral de Imigração e ao Conselho Nacional de Imigração do extinto Ministério do Trabalho (BRASIL, 2019).

A operacionalização dessa norma se fundamenta em três eixos distintos, mas convergentes. Distintos porque o primeiro se relaciona à necessidade de proceder à concessão de residência às vítimas de tráfico de pessoas, garantindo-lhes a proteção e a assistência, aferidas pela Lei n. 13.344, de 6 de outubro de 2016. O segundo está relacionado às predisposições da Lei de Migração, instituída pela Lei n. 13.445, de 24 de maio de 2017 e, o último, por sua vez, se fundamenta no Código Penal brasileiro, que contempla várias disposições normativas visando erradicar o trabalho escravo. Sua convergência está associada ao fato dos três eixos visarem à proteção e promoção dos direitos das vítimas, dada a vulnerabilidade destas, aferida na alínea "g", inciso II do art. 30, da Lei n. 13.445, de 24 de maio de 2017 e nos incisos I, II e III do art. 158, do Decreto n. 9.199, de 20 de novembro de 2017 (Lei de Migração) e respectivo Regulamento, que estabelecem que a autorização de residência poderá ser concedida à vítima de tráfico de pessoas, de trabalho escravo ou de violação de direito agravada por sua condição migratória, respectivamente.

A organização não governamental (ONG) Repórter Brasil destaca que a publicação da norma fortalece a proteção de imigrantes em situação de vulnerabilidade e amplia a garantia de acesso a direitos básicos desse grupo, vez que eram vistos erroneamente como "imigrantes ilegais", o que acaba reforçando a discriminação, os estereótipos e a própria condição de vulnerabilidade socioeconômica. Na opinião da $\mathrm{ONG}$, a discussão sobre os direitos dos migrantes avançou bastante e, aponta como marco essencial, o ano de 2017, marcado pela aprovação da Lei de Migração e respectivo regulamento, que regulamentam de forma específica essas matérias (REPÓRTER BRASIL, 2020).

A Portaria n. 87, de 23 de março de 2020, nos termos do art. 37 revoga a Portaria n. 374, de 8 de maio de 2017, que dispunha sobre a concessão de permanência no Brasil de estrangeiros considerados vítimas de tráfico de pessoas. Tratava-se de uma norma que surgiu da necessidade de desburocratização e simplificação dos procedimentos de regularização migratória de estrangeiros no Brasil aferida pela Lei n. 6.815, de 19 de agosto de 1980, que aprovou o Estatuto do Estrangeiro no Brasil (BRASIL, 1980). No que concerne, ainda, ao tráfico de pessoas, as alterações trazidas no art. $7^{\circ}$ da Lei n. 13.344, de 6 de outubro de 2016, ampliaram a salvaguarda da situação jurídica do estrangeiro no Brasil, em particular das vítimas de tráfico de pessoas, ao acrescer à Lei n. 6.815/1990, os artigos 18-A e 18-B:

a) o art.18-A concede "residência permanente às vítimas de tráfico de pessoas no território nacional, independentemente de sua situação migratória e de colaboração em procedimento administrativo, policial ou judicial." abrangendo também a família da vítima, a título de reunião familiar e isentando as vítimas do pagamento de multas e taxas previstas nos arts. 20,33, 125, inciso II, e 131 da Lei n. 6.815/1990; b) o art. 18-B determina que "Ato do Ministro de Estado da Justiça e Cidadania estabelecerá os procedimentos para concessão da residência permanente de que trata o art. 18-A."; e c) o art. 42-A dá garantias para que a vítima de tráfico de pessoas permaneça regular no Brasil, enquanto "tramitar pedido de regularização migratória” (VELHO; DIAS; ROCHA, 2017, p. 17).

Diante disso, com a aprovação da Lei de Migração e o respectivo regulamento parece óbvio revogar a Portaria n. 374, de 8 de maio de 2017, de modo a evitar a duplicação de esforços inerentes a regularização migratória de estrangeiros vítimas de tráfico de pessoas no Brasil, vez que esta nova norma passou a acautelar, mediante o art. 30, que a residência poderá ser autorizada por registro ao imigrante, ao residente fronteiriço ou ao visitante que tenha sido vítima de tráfico de pessoas, de trabalho escravo ou de violação de direito agravada por sua condição migratória, um aspecto reafirmado pelo respectivo regulamento, de acordo com o art. 158. Para além do fato 
de esses dois instrumentos serem mais abrangentes ao dispor sobre a concessão e autorização de residência à pessoa vítima de trabalho escravo ou de violação de direito agravada por sua condição migratória, grupos, igualmente vulneráveis, mas que não tinham uma proteção específica quanto às vítimas de tráfico de pessoas.

De acordo com o art. $1^{\circ}$ da Portaria n. 87/2020-MJSP, a solicitação de autorização de residência disciplinada nesta norma poderá ser apresentada em qualquer unidade da Polícia Federal. Nesse sentido, nos termos do art. $2^{\circ}$, caberá à autoridade migratória competente, por meio de juízo discricionário, avaliar e decidir sobre o pedido. Já o parágrafo $2^{\circ}$, inciso II do art. $6^{\circ}$ determina que quando se tratar de imigrante menor de dezoito anos ${ }^{27}$,que esteja desacompanhado ou separado de seu responsável legal e, na instrução do pedido, houver a auto declaração de filiação de que trata o inciso II do caput, o requerimento deverá observar ao disposto no art. 12 da Resolução Conjunta n. 1, de 9 de agosto de 2017, do Conselho Nacional dos Direitos da Criança e do Adolescente, do Comitê Nacional para os Refugiados, do Conselho Nacional de Imigração e da Defensoria Pública da União (BRASIL, 2020).

É importante salientar que essa resolução, que estabelece os procedimentos de identificação preliminar, atenção e proteção para criança e adolescente desacompanhados ou separados, e dá outras providências, por exemplo, de acordo com o art. $3^{\circ}$, os processos administrativos envolvendo criança ou adolescente desacompanhado ou separado tramitarão com absoluta prioridade e agilidade, devendo ser considerado o interesse superior da criança ou do adolescente na tomada de decisão.

De acordo com o art. $4^{\circ}$, a autorização de residência poderá ser requerida, com a anuência do imigrante pelo: Ministério Público; Defensoria Pública; Auditoria Fiscal do Trabalho; membros do Poder Judiciário; e Delegado de Polícia. Assim, satisfeitos os requisitos documentais dispostos na Portaria, será deferida a autorização de residência, cuja concessão será feita por prazo indeterminado, hipótese em que o imigrante será registrado e receberá a Carteira de Registro Nacional Migratório. $\mathrm{O}$ art. 10 concede algumas garantias ao imigrante, mormente: a possibilidade de livre exercício de atividade laboral no Brasil, nos termos da legislação vigente e a isenção de taxas e multas para obtenção de autorização de residência e obtenção de documento para regularização migratória, nos termos do parágrafo $3^{\circ}$ do art. 113 da Lei n. 13.445/2017 ${ }^{28}$, e do parágrafo $5^{\circ}$ do art. 312 do Decreto n. 9.199/2017. Já o art. 12 esclarece que se for constatada, a qualquer tempo, a omissão de informação relevante ou declaração falsa, será instaurado o processo de cancelamento da autorização de residência de que trata o art. 136 do Decreto n. 9.199/2017, sem prejuízo da adoção de outras medidas cabíveis ${ }^{29}$.

\section{CONCLUSÕES}

Atinente ao disposto na Lei n. 13.445/2017 - Lei de Migração e respectivo Regulamento, a Portaria n. 87/2020-MJSP se apresenta no plano operacional, uma vez que os primeiros dois instrumentos estabelecem conteúdo e limites para a autorização de residência às vítimas de tráfico de pessoas, de trabalho escravo ou de violação de direitos agravada por sua condição migratória.

Resulta claro, que com a aprovação dos dispositivos referidos, o Estado brasileiro vem reafirmar o seu comprometimento formal com a promoção e proteção dos direitos humanos das

\footnotetext{
${ }^{27}$ No Brasil, de acordo com art. $5^{\circ}$ da Lei n. 10.406, de 10 de janeiro de 2002, a Lei que institui o Código Civil, a menoridade cessa aos dezoito anos completos, quando a pessoa fica habilitada à prática de todos os atos da vida civil.

28 BRASIL. Lei n. 13.445, de 24 de maio de 2017. Institui a Lei de Migração. Disponível em: <http://www.planalto.gov.br/ccivil_03/_ato2015-2018/2017/lei/113445.htm> Acesso em: 18 abr. 2020.

${ }^{29}$ BRASIL. Decreto n. 9.199, de 20 de novembro de 2017. Regulamenta a Lei n. 13.445, de 24 de maio de 2017. Lei de Migração. Disponível em: <http://www.planalto.gov.br/ccivil_03/_ato2015-2018/2017/Decreto/D9199.htm>. Acesso em: 17 abr. 2020.
} 
pessoas afetadas pelo tráfico de pessoas e trabalho escravo, assim como qualquer imigrante que se encontre em situação de vulnerabilidade. Destaca-se, nesse interesse desiderato, o fato de ter incluído na legislação questões sobre violação de direitos agravada por condição migratória e por proteger imigrantes vítimas de abuso, em geral do sexo feminino, que sofram agressões e relacionamentos violentos.

Em suma, a Portaria, ao dispor sobre a concessão e os procedimentos de autorização de residência à pessoa que tenha sido vítima de tráfico de pessoas, de trabalho escravo ou de violação de direitos agravada pela sua condição migratória, estabelece a proteção das vítimas de tráfico de pessoas e do trabalho escravo, garantindo-lhes proteção e assistência, o que lhes permite o acesso a direitos básicos, assim como a possibilidade destes melhorarem a sua própria condição de vulnerabilidade socioeconômica.

\section{REFERÊNCIAS}

ALLAIN, Jean. Slavery in International Law of human exploitation and trafficking. Leiden: Martinus Nijhoff Publishers, 2013.

ALLAIN, Jean. Immanent critique: International Law and the dubious case-law on slavery. pp. 230-250, In: ALLAIN, Jean. The Law and Slavery: prohibiting human exploitation, Leiden: Brill Nijhoff, 2015.

ARBEX, Alexandre; GALIZA, Marcelo Galiza; OLIVEIRA, Tiago Oliveira. A política de combate ao trabalho escravo no período recente. In: Mercado de Trabalho, n. 64, pp. 111-137, abr. 2018.

BRASIL. Constituição da República Federativa do Brasil, de 5 de outubro de 1988(1988). Diário Oficial da União, Brasília, 5 out.1988. Disponível em:

<https://www.senado.leg.br/atividade/const/con1988/CON1988_05.10.1988/CON1988.asp>. Disponível em: 5 jun. 2020.

BRASIL. Decreto n. 5.017, de 12 de março de 2004. Promulga o Protocolo Adicional à Convenção das Nações Unidas contra o Crime Organizado Transnacional Relativo à Prevenção, Repressão e Punição do Tráfico de Pessoas, em Especial Mulheres e Crianças. Disponível em: <http://www.planalto.gov.br/ccivil_03/_Ato2004-2006/2004/Decreto/D5017.htm>. Acesso em: 13 maio 2020.

BRASIL. Decreto n. 5.948, de 26 de outubro de 2006. Aprova a Política Nacional de Enfrentamento ao Tráfico de Pessoas e institui Grupo de Trabalho Interministerial com o objetivo de elaborar proposta do Plano Nacional de Enfrentamento ao Tráfico de Pessoas - PNETP. Disponível em: 〈http://www.planalto.gov.br/ccivil_03/_Ato2004-2006/2006/Decreto/D5948.htm>. Acesso em: 13 maio 2020.

BRASIL. Decreto n. 9.199, de 20 de novembro de 2017. Regulamenta a Lei n. 13.445, de 24 de maio de 2017. Lei de Migração. Disponível em:

<http://www.planalto.gov.br/ccivil_03/_ato2015-2018/2017/Decreto/D9199.htm>. Acesso em: 17 abr. 2020.

BRASIL. Decreto n. 9.440, de 3 de julho de 2018. Aprova o III Plano Nacional para o Enfrentamento ao Tráfico de Pessoas. Disponível em: <https://www.justica.gov.br/sua- 
protecao/trafico-de-pessoas/politica-brasileira/dec-9440-18-iii-plano.pdf>. Acesso em: 15 maio 2020 .

BRASIL. Lei n. 13.344, de 6 de outubro de 2016. Dispõe sobre prevenção e repressão ao tráfico interno e internacional de pessoas e sobre medidas de atenção às vítimas; altera a Lei n. 6.815, de 19 de agosto de 1980. Disponível em: <http://www.planalto.gov.br/ccivil_03/_ato20152018/2016/lei/113344.htm>. Acesso em: 28 abr. 2020.

BRASIL. Lei n. 13.445, de 24 de maio de 2017. Institui a Lei de Migração. Disponível em: <http://www.planalto.gov.br/ccivil_03/_ato2015-2018/2017/lei/113445.htm> Acesso em: 18 abr. 2020.

BRASIL. Lei n. 6.815, de 19 de agosto de 1980. Estatuto do Estrangeiro. Disponível em: <https://presrepublica.jusbrasil.com.br/legislacao/108497/estatuto-do-estrangeiro-lei-6815-80>. Acesso em: 16 abr. 2020.

BRASIL. Portaria n. 87, de 23, de março de 2020. Dispõe sobre a concessão e os procedimentos de autorização de residência à pessoa que tenha sido vítima de tráfico de pessoas, de trabalho escravo ou de violação de direito agravada por sua condição migratória. Disponível em: <http://www.in.gov.br/en/web/dou/-/portaria-n-87-de-23-de-marco-de-2020-249440047>. Acesso em: 02 maio 2020.

CONSELHO NACIONAL DE JUSTIÇA. Portaria n. 133/2018. Institui o Comitê Interinstitucional destinado a avaliar a integração das metas do Poder Judiciário às metas e indicadores dos Objetivos de Desenvolvimento Sustentável (ODS), Agenda 2030. Disponível em: <https://atos.cnj.jus.br/atos/detalhar/2721>. Acesso em: 10 jun. 2020.

CORRÊA DA SILVA, Waldimeiry. Formas Contemporáneas de Esclavitud. Sevilla: Servicio de Publicaciones de la Universidad de Sevilla, 2011. [Tesis doctoral] 499p. Disponível em: <https://idus.us.es/handle/11441/23966>. Acesso em: 14 jun. 2020.

CORRÊA DA SILVA, Waldimeiry; GÓES, Karine Dantas Góes. Proteção contra as Formas Contemporânea de Escravidão - Uma Garantia Constitucional. In: Brasiliana - Journal for Brazilian Studies. v. 2, n. 2, p. 289-312, novembro, 2013. Disponível em: <https://tidsskrift.dk/bras/article/view/9081>. Acesso em: 14 jun. 2020.

CORRÊA DA SILVA, Waldimeiry. Tráfico de pessoas e trabalho forçado: uma sinergia negativa. In: Revista Latino-Americana dos Direitos Humanos. v. 4, n. 1, p. 84-92, 2013. Disponível em: <https://periodicos.ufpa.br/index.php/hendu/article/view/1717>. Acesso em: 12 jun. 2020.

CORRÊA DA SILVA, Waldimeiry. Regime Internacional de Enfrentamento ao Tráfico de Pessoas: avanços e desafios para a proteção dos direitos humanos. Rio de Janeiro: Lumen Juris, 2018.

FIGUEIRA, Ricardo Rezende; PRADO, Adonia Antunes; PALMEIRA, Rafael Franca Palmeira. L'esclavage contemporain et ses transformations en Amazonie brésilienne: les témoignages des victimes. In: Sciences Humaines et Sociales, Brésil(s) [En ligne], v. 11, maio, 2017. Disponível em: <https://journals.openedition.org/bresils/2186\#ftn3>. Acesso em: 10 jun. 2020. 
FIGUEIRA; Ricardo Rezende; ESTERCI, Neide. Slavery in Today's Brazil: Law and Public Policy. In: Latin American Perspectives, v. 44 issue: 6, p. 77-89, november 1, 2017. Disponível em: <https://journals.sagepub.com/doi/abs/10.1177/0094582X17699913>. Acesso em: 10 jun. 2020.

INTERNATIONAL LABOUR ORGANIZATION; WALK FREE FOUNDATION; INTERNATIONAL ORGANIZATION FOR MIGRATION. Global Estimates of Modern Slavery: Forced labour and forced marriage. Geneva: International Labour Office, 2017. Disponível em: <https://www.ilo.org/wcmsp5/groups/public/---dgreports/--dcomm/documents/publication/wcms_575479.pdf>. Acesso em: 13 jun. 2020.

LIMA, Priscila Nottingham de. Tráfico de mulheres e exploração sexual. Fortaleza: EDMETA EdUECE, 2012.

MINISTÉRIO DA JUSTIÇA. II Plano Nacional de Enfrentamento ao Tráfico de Pessoas. Brasília: SNJ, 2013.

MINISTÉRIO DA JUSTIÇA. Plano Nacional de Enfrentamento ao Tráfico de Pessoas. Brasília: SNJ, 2008.

MINISTÉRIO DA JUSTIÇA. Relatório nacional sobre o tráfico de pessoas: dados 2014 a 2016. Brasília: UNODC, 2017. Disponível em: <https://www.justica.gov.br/sua-protecao/trafico-depessoas/publicacoes/relatorio-de-dados.pdf>. Acesso em: 21 maio 2020.

OBSERVATÓRIO DA ERRADICAÇÃO DO TRABALHO ESCRAVO E DO TRÁFICO DE PESSOAS. Disponível em: < https://smartlabbr.org/trabalhoescravo/ > Acesso em: 20 set. 2020.

ORGANIZAÇÃO INTERNACIONAL DE TRABALHO. Trabalho forçado. OIT Brasília. Disponível em: <https://www.ilo.org/brasilia/temas/trabalho-escravo/lang-pt/index.htm\#: :text=As\%20mulheres\%20representam\%2099\%25\%20das,e \%2084\%25\%20dos\%20casa mentos\%20for\%C3\%A7ados.\&text=Os\%20trabalhadores\%20migrantes\%20e\%20os,0\%20site\%20global \%20da\%200IT\%20.>. Acesso em: 10 jun. 2020.

ORGANIZAÇÃO INTERNACIONAL DO TRABALHO. Combatendo o Trabalho Escravo Contemporâneo: o exemplo do Brasil. Brasília: Escritório Internacional do Trabalho, 2010. 194p. Disponível em: <https://www.ilo.org/wcmsp5/groups/public/---americas/---ro-lima/---ilobrasilia/documents/publication/wcms_227300.pdf>. Acesso em: 14 maio 2020.

PATTERSON, Orlando. Escravidão e morte social: um estudo comparativo. Trad. Fábio Duarte Joly. São Paulo: Editora da Universidade de São Paulo, 2008.

REPÓRTER BRASIL. Brasil: Concessão de residência a vítimas de trabalho escravo e tráfico de pessoas é garantida pelo Ministério da Justiça. Repórter Brasil, 27 mar. 2020. Disponível em $<$ http://escravonempensar.org.br/portaria-do-ministerio-da-justica-possibilita-a-concessao-deresidencia-a-vitimas-de-trabalho-escravo-e-trafico-de-pessoas/>. Acesso em: 02 maio 2020.

SAKAMOTO, Leonardo. O trabalho escravo contemporâneo. In: SAKAMOTO, Leonardo (org.). Escravidão Contemporânea. São Paulo: Contexto, 2020. p. 7-16. 
SALES, Jeane; FIGUEIRA, Vitor Araújo. Trabalho análogo ao escravo no Brasil: natureza do fenômeno e regulação. In: Revista da ABET: Brazilian Journal Of Labour Studies, v. 12, n. 2, p. 29-47, jul.-dez., 2013. Disponível em:

<https://periodicos.ufpb.br/ojs2/index.php/abet/article/view/20206>. Acesso em: 9 jun. 2020.

SOUZA, Mércia Cardoso de. Tráfico de pessoas para trabalho forçado no âmbito do Mercosul: Direito e Política para os Direitos Humanos. 2016. 566 f. Tese (Doutorado em Direito Constitucional) - Universidade de Fortaleza, Fortaleza, 2016. Disponível em:

$<$ https://uol.unifor.br/oul/ObraBdtdSiteTrazer.do?method=trazer\&ns=true\&obraCodigo=99954>. Acesso em: 25 maio 2020.

TPIY. Caso Promotor Vs. Dragoljub Kunarac, Radomir Kovac e Zoran Vukovic (doravante denominado Caso Promotor Vs. Kunarac), n. IT-96-23. Câmara de $1^{a}$ Instância, Sentença de 22 de fevereiro de 2001; e n. IT-96- 23-A, Câmara de Apelações, Sentença de 12 de junho de 2002.

UNITED NATIONS. United Nations Treaty collation: Status of Treaty. New York: Office of legal affairs, 2020. Disponível em:

$<$ https://treaties.un.org/pages/ViewDetails.aspx?src=TREATY\&mtdsg_no=XVIII-12a\&chapter $=18 \&$ clang=_en $>$. Acesso em: 31 maio 2020.

UNODC. Global Report on Trafficking in Persons. Nova York: Publicação das Nações Unidas, 2016. Disponível em: <https://www.unodc.org/documents/data-andanalysis/glotip/2016_Global_Report_on_Trafficking_in_Persons.pdf $>$. Acesso em: 20 maio 2020.

UNODC. Relatório Global sobre o Tráfico de Pessoas. Nova York: Publicação das Nações Unidas, 2018. Disponível em: <https://www.unodc.org/documents/lpobrazil//Topics_TIP/Publicacoes/TiP_PT.pdf>. Acesso em: 24 maio 2020.

VELHO, Caroline de Azevedo; DIAS, Jadson Juarez Cavalcante; ROCHA, Mário Henrique da. O combate ao tráfico de pessoas e a adequação da legislação nacional às normas internacionais. In: SCAMPINI, Stella Fátima (Org.). Tráfico de pessoas. Brasília: Ministério Público Federal, 2017. 198p. p. 10-19. Disponível em: <http://www.mpf.mp.br/atuacaotematica/ccr2/publicacoes/coletaneas-deartigos/003_17_coletanea_de_artigos_trafico_de_pessoas.pdf> Acesso em: 15 abr. 2020.

WALK FREE FOUNDATION. Global Slavery Index. Walk Free Foundation: Path, 2018. Disponível em: <https://www.globalslaveryindex.org/resources/downloads/>. Acesso em: 12 jun. 2020. 